\title{
The effect of an aerobic exercise program on the quality of life in children with cancer
}

\author{
Ezzat Khodashenas ${ }^{1}$, Zahra Badiee ${ }^{1}$, Mehdi Sohrabi $^{2}$, Ali Ghassemi ${ }^{1}$, Vahideh Hosseinzade ${ }^{3}$ \\ ${ }^{1}$ Department of Pediatrics, ${ }^{3}$ Faculty of Medicine, Mashhad University of Medical Sciences, Mashhad, Iran; ${ }^{2}$ Ferdowsi \\ University of Mashhad, Mashhad, Iran. \\ E-mail: Khodashenase@mums.ac.ir
}

Received: 29th January 2017, Revised: 24th March 2017, Accepted: 23th April 2017

SUMMARY: Khodashenas E, Badiee Z, Sohrabi M, Ghassemi A, Hosseinzade $\mathrm{V}$. The effect of an aerobic exercise program on the quality of life in children with cancer. Turk J Pediatr 2017; 59: 678-683.

Aerobic exercise such as physical activity plays an essential role for a healthy development for children undergoing chemotherapy and radiation therapy. The aim of this study was to examine the effectiveness of an aerobic exercise program on quality of life in children undergoing cancer treatment. Patients diagnosed with acute lymphoblastic leukemia (ALL), undergoing chemotherapy, were divided into two groups; the control group received the routine treatment with activities of daily living and the interventional group received routine treatment in addition to an aerobic exercise program. Data was collected using the pediatric quality of life questionnaires (PedsQL version 4) before and after the training program. We enrolled 20 cancer patients, who were referred to Dr. Sheikh Children's Hospital in Mashhad, Iran; 8 (40\%) and 12 $(60 \%)$ of the patients were female and male, respectively. The results show a significant association in the pain and injury subscale $(\mathrm{p}=0.002)$, improving in interventional groups after test compared to the control groups. The reports of parents of the children's quality of life showed significant association in the pain and injury subscale $(\mathrm{P}=0.002)$, and cognitive problems subscale at school $(\mathrm{P}=0.039)$. The regular exercise and psychosocial program intervention can improve wellbeing and thereby enhance efficacy of the children during treatment.

Key words: aerobic exercise, childhood cancer, physical activity, quality of life.

Childhood cancer and its treatment have the most important impact on a child's physical and mental wellbeing and increased long-term survival. ${ }^{1}$ Chemotherapy and radiation therapy have the opposite effect on these children, radiation therapy often causes lung fibrosis and chemotherapy causes anemia, effect on cardiac function, skeletal muscle mass, and induces gastrointestinal toxicities that can interfere with nutrition. Thus, individuals undergoing cancer treatment can experience fatigue even during normal activities of daily living. ${ }^{2}$ Longterm management in these children based on rehabilitation interventions cause an increase in the number of childhood cancer survivors (CCS) and its now obvious management of its treatment can significantly have an impact on long-term health, quality of life in these children and reduce the morbidity and mortality rate. ${ }^{3}$

A growing number of studies are now focusing on effects of physical activity as an essential role for a healthy development of children undergoing chemotherapy and radiation therapy. ${ }^{4}$ Physical activity during and after treatment has been shown to increase the positive effects on quality of life and increased long-term survival. ${ }^{5}$ Regular physical activity appears to act as a natural anti-inflammatory and antioxidant strategy to improve function and antioxidant defenses in these patients. ${ }^{6}$

Aerobic exercise such as physical activity, defined as rhythmical contraction and relaxation, has been suggested for rehabilitation of cancer patients during and after treatment for the problem of energy loss. ${ }^{7}$ It is expected that 
the impact of aerobic exercise will increase the success of therapy for childhood cancers. The aim of this study was to examine the effectiveness of an aerobic exercise program on quality of life of children undergoing cancer treatment.

\section{Material and Methods}

In this study, the participants were assigned using random selection method. Inclusion criteria consisted of all patients aged between 5-12 years, diagnosed with acute lymphoblastic leukemia (ALL) undergoing chemotherapy, or in the remission phase or after the induction phase less than one year after treatment. Exclusion criteria consisted of patients who their parents did not consent to enrolling in the study or there was not sufficient information in their documents, having cardiovascular or lung diseases, having less than 50,000 platelets count or a bleeding disorder. Finally, 20 patients were enrolled. Also, the study protocol was reviewed and approved by Ethics Committees of Mashhad University of Medical Sciences.

\section{Study design}

We recorded data regarding all 20 children (8 females and 12 males), participants were between the ages of 5-12 years who were admitted for ALL at the Dr. Sheikh children's hospital, Mashhad, Iran, during 2015-2016. The patients received chemotherapy for standard risk ALL from Lanzkowsky. Data were collected using the pediatric quality of life questionnaires (PedsQL version 4) before and after the training program. The PedsQL 4.0 Scales had 23-item encompass the following: physical functioning, emotional functioning, social functioning, and school functioning.

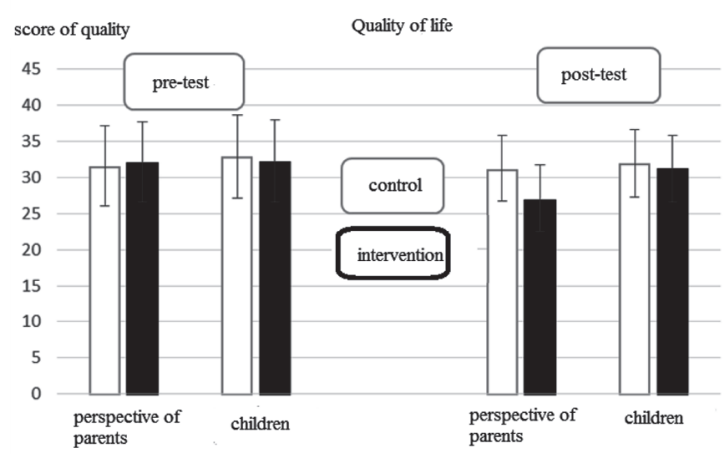

Fig. 1. Compare the total quality of life score between control and intervention Group Pre- and Post-test.

\section{Training program}

The following guidelines suggested by the authors of the original version of the PedsQL ${ }^{\mathrm{TM}}$ 4.0 Cancer Module, to evaluate the generic measures of quality of life (QoL) and for the convergent psychometric validation (8), were the original English version of the PedsQL ${ }^{\mathrm{TM}} 4.0$ translated into Persian, the authors efforts were devoted to achieving linguistic and conceptual equivalence of the investigators. In this step, we performed content validity by panel of experts and pilot testing, then accuracy and reliability testing suitable.

The participants were divided into two groups; the control group who received the routine treatment with daily living activities and the experimental group who received the routine treatment in addition to the aerobic exercise program (Includes walking, running and different forms of playing). Each patient received three exercise sessions per week during 12 weeks, each of which took 60 minutes, by lower intensity with 60 to $85 \%$ of maximum heart rate. The pediatric quality of life questionnaires (PedsQL version 4) were completed for the two groups (children and Parent reports for children) before and after the training program.

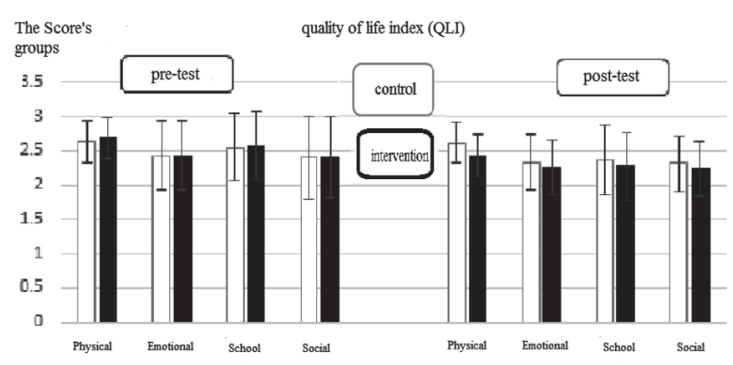

Fig. 2. The score of subscales of the quality of life for children.

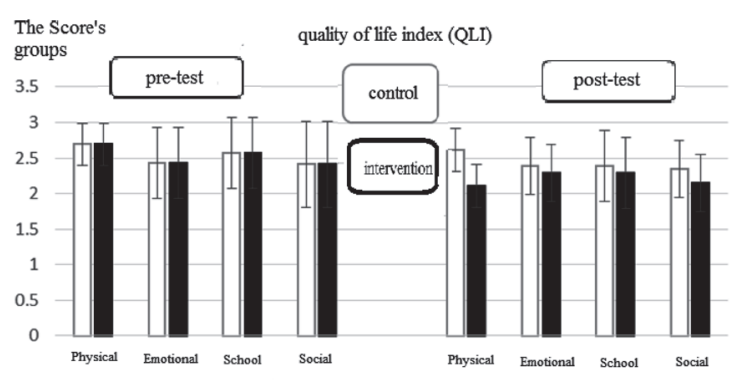

Fig. 3. The score of subscales of the quality of life (reports of parents) 


\section{Statistical analysis}

Demographic data on subjects was analyzed with using descriptive and analytical statistics. On the other hand, Data on pre and post in groups were compared with using Student's t-test and Chi-square test. Table I-IV and Figure 1-3 demonstrate the statistical analysis.

\section{Results}

A total of 20 children; 10 intervention and 10 control were enrolled in our study.

The mean age was 8.8 years (age range, 5-12 year) and 10.1 years (age range, 5-12 year) in control and intervention group, respectively. No significant association was observed between the intervention group and control group for gender $(\mathrm{P}=0.325)$.

This study showed no significant difference between the quality of life index (QLI) for the intervention group and control group at differences of pre and post-test $(\mathrm{P}>0.05)$ (Table I-III and Fig.1). The two groups had same condition about variable of quality of life, there was significant association concerning the pain and injury subscale $(\mathrm{P}=0.002)$ (Table I and
Fig.2), However, in regard to reports of parents, the children's quality of life, had significant association between the intervention group and control group in post-test $(\mathrm{P}=0.019)$ (Table IV and Fig.1). In the reports of parents, concerning children's quality of life, the results show a significant association in pain and injury at physical functioning $(\mathrm{p}=0.002)$, and cognitive problems at school functioning $(\mathrm{P}=0.039)$ (Table I and Fig. 3). In addition, from the reports of parents, the children's quality of life in pain and injury at physical functioning and cognitive problems at school functioning improved in interventional group after test compared to the control groups.

The comparison of QLI for children using the dependent t-test showed no significant association between pre- and post-test in the control and intervention group $(\mathrm{P}>0.05)$ (Table 3, Fig.1). In reports of parents, pain and injury of physical functioning $(\mathrm{p}=0.04)$, concern about of treatment of emotional functioning $(\mathrm{P}=0.02)$, and cognitive problems of school functioning $(\mathrm{P}=0.03)$ had significant association between pre - and post-test (Table II) in interventional group compared to the control group.

Table I. Compare Quality of Life Index (QLI) in Children and reports of Parents Pre- and Post-test by Independent t-test.

\begin{tabular}{|c|c|c|c|c|c|c|c|c|}
\hline \multirow{2}{*}{$\begin{array}{l}\text { Quality of } \\
\text { Life Index } \\
\text { QLI }\end{array}$} & \multirow[t]{2}{*}{ Variable } & & \multicolumn{2}{|c|}{$\begin{array}{l}\text { Mean difference } \\
\text { between groups }\end{array}$} & \multicolumn{2}{|c|}{$\mathrm{T}$} & \multicolumn{2}{|c|}{$\mathrm{P}$} \\
\hline & & & Pre-test & Post-test & Pre-test & Post-test & Pre-test & Post-test \\
\hline \multirow[t]{6}{*}{ Physical } & \multirow[t]{2}{*}{ Pain and injury } & Children & 0.5 & 2.70 & 0.41 & 3.61 & 0.68 & 0.002 \\
\hline & & Parents & 1.6 & 2.8 & 1.45 & 3.93 & 0.16 & 0.002 \\
\hline & \multirow[t]{2}{*}{ Nausea } & Children & -2.5 & -1.10 & 1.15 & 0.75 & 0.26 & 0.46 \\
\hline & & Parents & -1.4 & 0.8 & -0.78 & 0.51 & 0.44 & 0.61 \\
\hline & \multirow{2}{*}{$\begin{array}{l}\text { Appearance and } \\
\text { countenance }\end{array}$} & Children & 1.60 & 0.40 & 0.87 & 0.25 & 0.39 & 0.79 \\
\hline & & Parents & 1.8 & 2.5 & 1.06 & 1.49 & 0.30 & 0.15 \\
\hline \multirow[t]{6}{*}{ Emotional } & \multirow[t]{2}{*}{ Anxiety } & Children & -1 & 2.20 & 0.05 & 1.77 & 0.95 & 0.09 \\
\hline & & Parents & 1.86 & -0.6 & 0.37 & -0.37 & 0.71 & 0.71 \\
\hline & \multirow{2}{*}{$\begin{array}{l}\text { Anxiety about } \\
\text { see a doctor }\end{array}$} & Children & -1.30 & 0.30 & -0.78 & 0.20 & 0.44 & 0.86 \\
\hline & & Parents & 1.61 & -0.3 & 1.36 & -0.34 & 0.19 & 0.73 \\
\hline & \multirow{2}{*}{$\begin{array}{l}\text { Concern about } \\
\text { treatment }\end{array}$} & Children & -2.10 & 0.80 & -1.26 & 0.87 & 0.22 & 0.39 \\
\hline & & Parents & 1.56 & 1.7 & -1.47 & 1.11 & 0.15 & 0.27 \\
\hline \multirow[t]{2}{*}{ School } & \multirow{2}{*}{$\begin{array}{l}\text { Cognitive } \\
\text { problems }\end{array}$} & Children & -3.7 & 2.0 & -1.56 & 0.99 & 0.13 & 0.33 \\
\hline & & Parents & 1.59 & 1.3 & -0.15 & 1.22 & 0.87 & 0.03 \\
\hline \multirow[t]{2}{*}{ Social } & \multirow[t]{2}{*}{ Communication } & Children & 1.61 & 2.20 & -0.37 & 1.68 & 0.71 & 0.11 \\
\hline & & Parents & 1.49 & 2.4 & -0.26 & 1.72 & 0.79 & 0.10 \\
\hline
\end{tabular}


Table II. Compare Quality of Life Index (QLI) in Children and reports of Parents at Control and InterventionGroups by Dependent t-test.

\begin{tabular}{|c|c|c|c|c|c|c|c|c|}
\hline \multirow{2}{*}{$\begin{array}{l}\text { Quality of } \\
\text { Life Index } \\
\text { QLI }\end{array}$} & \multirow[t]{2}{*}{ Variable } & & \multicolumn{2}{|c|}{$\begin{array}{l}\text { Mean difference } \\
\text { between groups }\end{array}$} & \multicolumn{2}{|c|}{$\mathrm{T}$} & \multicolumn{2}{|c|}{$\mathrm{P}$} \\
\hline & & & $\begin{array}{l}\text { Cont- } \\
\text { group }\end{array}$ & $\begin{array}{l}\text { Inter- } \\
\text { group }\end{array}$ & $\begin{array}{l}\text { Cont- } \\
\text { group }\end{array}$ & $\begin{array}{l}\text { Inter- } \\
\text { group }\end{array}$ & $\begin{array}{l}\text { Cont- } \\
\text { group }\end{array}$ & $\begin{array}{l}\text { Inter- } \\
\text { group }\end{array}$ \\
\hline \multirow[t]{6}{*}{ Physical } & \multirow[t]{2}{*}{ Pain and injury } & Children & 0.7 & 0.68 & 0.52 & 2.78 & 0.63 & 0.12 \\
\hline & & Parents & 0.68 & 2.59 & 0.62 & 2.24 & 0.70 & 0.04 \\
\hline & \multirow[t]{2}{*}{ Nausea } & Children & -1.01 & -1.53 & 1.16 & 0.69 & 0.31 & 0.45 \\
\hline & & Parents & -0.91 & -1.38 & 1.01 & 0.63 & 0.42 & 0.45 \\
\hline & \multirow{2}{*}{$\begin{array}{l}\text { Appearance and } \\
\text { countenance }\end{array}$} & Children & 1.06 & 0.58 & 0.91 & 0.25 & 0.41 & 0.79 \\
\hline & & Parents & 0.86 & 0.56 & 0.92 & 0.24 & 0.38 & 0.79 \\
\hline \multirow[t]{6}{*}{ Emotional } & \multirow[t]{2}{*}{ Anxiety } & Children & -1.0 & 0.79 & 0.089 & 1.97 & 0.82 & 0.21 \\
\hline & & Parents & -1.0 & 1.21 & 0.18 & 1.29 & 0.71 & 0.21 \\
\hline & \multirow{2}{*}{$\begin{array}{l}\text { Anxiety about } \\
\text { see a doctor }\end{array}$} & Children & -1.09 & 0.48 & -0.81 & 0.45 & 0.39 & 0.86 \\
\hline & & Parents & -0.79 & 0.48 & -0.77 & 0.46 & 0.48 & 0.86 \\
\hline & \multirow{2}{*}{$\begin{array}{l}\text { Concern about } \\
\text { treatment }\end{array}$} & Children & -1.12 & 0.13 & -1.25 & 1.17 & 0.28 & 0.11 \\
\hline & & Parents & -0.92 & 1.39 & -1.05 & 1.70 & 0.28 & 0.02 \\
\hline \multirow[t]{2}{*}{ School } & \multirow{2}{*}{$\begin{array}{l}\text { Cognitive } \\
\text { problems }\end{array}$} & Children & -1.7 & 0.85 & -1.25 & 1.19 & 0.28 & 0.13 \\
\hline & & Parents & -0.7 & 1.70 & -1.46 & 1.92 & 0.62 & 0.03 \\
\hline \multirow[t]{2}{*}{ Social } & \multirow[t]{2}{*}{ Communication } & Children & 1.61 & 0.91 & -0.62 & 1.18 & 0.61 & 0.11 \\
\hline & & Parents & 0.61 & 1.10 & -0.71 & 1.13 & 0.61 & 0.11 \\
\hline
\end{tabular}

Figure 2 and 3 show the score of subscales of the quality of life has been not changed for children and their parent's report in control groups but it improved for children and their parent's report in intervention groups.

\section{Discussion}

Children with cancer under treatment are at an increased risk of expanding damaging physiological and psychosocial effects due to their medical treatments. The incidence of these effects may be exacerbating the complications of chemotherapy and cause deterioration of quality of life in these children. ${ }^{9}$ Oeffinger et al. ${ }^{10}$ reported that 30 years after cancer diagnosis in childhood, about $73 \%$ of children had a chronic health condition. Thus, efforts are now being managed toward improving the quality of life of these children. Other experience show the physical exercise programs along with chemotherapy improve the quality of life of patients. ${ }^{11-14}$ In this study, we evaluated the effectiveness of an aerobic exercise program on quality of life in children undergoing cancer treatment. Our results show QLI is not significant in any of the variables of quality of life between the intervention and control group before the aerobic exercise program. Comparison of results of QLI after exercise show the quality of life in pain and injury at physical working improved in interventional group. The comparison of the total of quality of life scores was significant between the results before and after the exercise program and the reports of parents. Keats and CulosReed ${ }^{15}$ demonstrated that combined physical exercise and chemotherapy could significantly improve the quality of life scores. Wolin et al. ${ }^{16}$ reported, using regular physical activity along with chemotherapy has potential benefits for both adult and pediatric hematological cancer survivors. Braam et al. ${ }^{1}$ reported exercise could be reducing side effects and improving the quality of life of patients before, during and after treatment. The growing trend toward using physical exercise along with chemotherapy could be improving the quality of life at children under cancer treatment ${ }^{17}$. In a previous report, the authors have shown aerobic exercise significantly improve the quality of life of cancer patients under chemotherapy. ${ }^{18}$ Sharkey et al. ${ }^{19}$ 
Table III. Compare the Quality of Life in Control and Interventional Children Groups Pre- and Post-test.

\begin{tabular}{lccc}
\hline Variable & Mean difference between groups & $\mathrm{T}$ & $\mathrm{P}$ \\
\hline Quality life pre-test study & 1.2 & 2.89 & 0.15 \\
Quality life post-test study & 1.9 & 2.19 & 0.11 \\
\hline
\end{tabular}

Table IV. Compare the Quality of Life in Control and Interventional Parent's report Groups Pre- and Post-test.

\begin{tabular}{lccc}
\hline Variable & Mean difference between groups & $\mathrm{T}$ & $\mathrm{P}$ \\
\hline Quality life pre-test study & 1.4 & 2.12 & 0.11 \\
Quality life post-test study & 2.3 & 3.11 & 0.019
\end{tabular}

and Collett et $a .^{20}$ investigated the effects of exercise programs on young adult survivors of childhood cancer during treatment. They observed improvements in functional capacity and tolerance in these children. Sharkey et al. ${ }^{19}$ reported that physical activity improved the range of survival in interventional groups compared to control. But, Collett et al. ${ }^{20}$ did not observe any differences between survivors randomized between two groups. Baumann et al. ${ }^{13}$ suggested according clinical findings that exercise interventions during medical treatment, especially in patients with ALL, has a positive effect on fatigue and quality of life. Our study was measured to investigate the quality of life in different areas of physical, emotional, social, and school functioning and the scores obtained in these areas was desirable but quality of life statistical significance was only in some functions such as physical performance. However, our results show the total of quality of life scores improvement in interventional group after the training program. But for each variable, results were not significant but the scores obtained after the program, was favorable and suggest improved quality of life after aerobic exercise and no significance could be due to the low number of cases.

Reports of parents were different particularly with respect to their child's physical, social, and school functioning compared to perspective of children based on parents who have concerns about their child. ${ }^{21}$ Barakat et al. ${ }^{22}$ believed that reports of parents was not shown quality life of children under chemotherapy. Russell et al. ${ }^{23}$ and Vlachioti et al. ${ }^{24}$ showed quality life of children according to reports of parents was significantly lower in the domains of pain and discomfort, nausea, anxiety and communication than children off treatment. Also, Vlachioti et $\mathrm{al}^{24}$ reported children's quality of life was not the same as report of parents. However, physical and psychological interventions should be design and implement with their gender (male and female differences) .n this study; we reported the results on mean difference between groups according to both reports of parents and children. The level of activity was same in both genders. In addition, parent's reports in pain and injury (physical functioning), concern about of treatment (emotional functioning), and cognitive problems (school functioning) have better quality of life than children's reports. It can be concluded that, from the reports of the parents, the quality of life of children in the pain and injury has improved. This significance in scale of parents would indicate better realization and understanding of parents of the quality of life questionnaire than children. Our results show QLI from the reports of the parents was not significant in any of the variables of quality of life between the intervention and control groups before the aerobic exercise test. Although other variables did not achieve statistical results, the perspectives of parents in the most variables scores show the quality of life of children improving after the exercise session.

Cancer and chemotherapy can affect a child's capability to perform normal daily activities and affect the child's psychology, due to diminishing these activities. Thus, regular exercise and psychosocial program intervention can improve wellbeing and thereby enhance efficacy of the children during treatment.

\section{Acknowledgement}

This article is taken from the graduate thesis of student with the number of 7223 at Mashhad University of Medical Sciences. 


\section{REFERENCES}

1. Braam KI, Van Dijk EM, Veening MA, et al. Design of the Quality of Life in Motion (QLIM) study: a randomized controlled trial to evaluate the effectiveness and cost-effectiveness of a combined physical exercise and psychosocial training program to improve physical fitness in children with cancer. BMC cancer 2010; 10: $1-9$.

2. Braam KI, Van der Torre P, Takken T, Veening MA, Van Dulmen-den Broeder E, Kaspers GJ. Physical exercise training interventions for children and young adults during and after treatment for childhood cancer. Cochrane Database Syst Rev 2013; 30: 1-57.

3. Lipshultz SE, Adams MJ, Colan SD, et al. Longterm cardiovascular toxicity in children, adolescents, and young adults who receive cancer therapy: pathophysiology, course, monitoring, management, prevention, and research directions a scientific statement from the american heart association. Circulation 2013; 128: 1927-1995.

4. Götte M, Kesting SV, Winter CC, Rosenbaum D, Boos $\mathrm{J}$. Motor performance in children and adolescents with cancer at the end of acute treatment phase. Eur J Pediatr 2015; 174: 791-799.

5. Crank H, Campbell A, Stevinson C. Physical activity for cancer. Clinical Exercise Science: Routledge; 2016: 102-122

6. Winter C, Müller C, Hoffmann C, Boos J, Rosenbaum D. Physical activity and childhood cancer. Pediatr Blood Cancer 2010; 54: 501-510.

7. Chyu C, Halnon N. Exercise Training in Cancer Survivors. Curr Oncol Rep 2016; 18: 1-9.

8. Punzalan JM, Canonigo BB, Cabansag MRF, et al. A Cross-Cultural Validation of a Quality of Life Measure Using the Simple Measure of the Impact of Lupus Erythematosus in Youngsters (SMILEY() among Filipino Pediatric Lupus Patients. Open Urol Nephrol J 2016; 9: 60-66.

9. Beulertz J, Prokop A, Rustler V, Bloch W, Felsch M, Baumann FT. Effects of a 6-Month, Group-Based, Therapeutic Exercise Program for Childhood Cancer Outpatients on Motor Performance, Level of Activity, and Quality of Life. Pediatr Blood Cancer 2016; 63: 127-132.

10. Oeffinger KC, Mertens AC, Sklar CA. et al. Chronic health conditions in adult survivors of childhood cancer. N Engl J Med 2006; 355: 1572-1582.

11. Juan AFS, Wolin K, Lucía A. Physical activity and pediatric cancer survivorship. Recent Results Cancer Res 2011; 186: 319-347.
12. Soares-Miranda L, Fiuza-Luces C, Lassaletta A, et al Physical activity in pediatric cancer patients with solid tumors (PAPEC): Trial rationale and design. Contemp Clin Trials 2013; 36: 106-115.

13. Baumann FT, Bloch W, Beulertz J. Clinical exercise interventions in pediatric oncology: a systematic review. Pediatr Res 2013; 74: 366-374.

14. Huang T-T, Ness KK. Exercise interventions in children with cancer: a review. Int J Pediatr 2011; 2011: 1-11.

15. Keats MR, Culos-Reed SN. A community-based physical activity program for adolescents with cancer (project TREK): program feasibility and preliminary findings. J Pediatr Hematol Oncol 2008; 30: 272-280.

16. Wolin KY, Ruiz J, Tuchman H, Lucia A. Exercise in adult and pediatric hematological cancer survivors: an intervention review. Leukemia 2010; 24: 1113-1120.

17. O’Neill RF, Haseen F, Murray LJ, O'Sullivan JM, Cantwell MM. A randomised controlled trial to evaluate the efficacy of a 6-month dietary and physical activity intervention for patients receiving androgen deprivation therapy for prostate cancer. J Cancer Surviv 2015; 9: 431-440.

18. Yağlı NV, Șener G, Arıkan H, et al. Do yoga and aerobic exercise training have impact on functional capacity, fatigue, peripheral muscle strength, and quality of life in breast cancer survivors? Integr Cancer Ther 2015; 14: $125-132$.

19. Sharkey AM, Carey AB, Heise CT, Barber G. Cardiac rehabilitation after cancer therapy in children and young adults. Am J Cardiol 1993; 71: 1488-1490.

20. Collett B, Acosta A, Whitsett S, McTiernan A, Friedman D. Exercise intervention for pediatric cancer survivors: Feasibility and preliminary efficacy. J Clin Oncol2007; 25: 20013-20013.

21. Khetani MA, Collett BR, Speltz ML, Werler MM Health-related quality of life in children with hemifacial microsomia: parent and child perspectives. J Dev Behav Pediatr 2013; 34: 661-668.

22. Barakat LP, Marmer PL, Schwartz LA. Quality of life of adolescents with cancer: family risks and resources. Health Qual Life Outcomes 2010; 8: 1-8.

23. Russell KM, Hudson M, Long A, Phipps S. Assessment of health-related quality of life in children with cancer Cancer 2006; 106: 2267-2274.

24. Vlachioti E, Matziou V, Perdikaris P, et al. Assessment of quality of life of children and adolescents with cancer during their treatment. Jpn J Clin Oncol 2016; 46: 453-461. 